\title{
Professional Development for Teaching Students in Poverty and Impacting Teacher Beliefs
}

\author{
Barbara M. Wickham and Carol A. Mullen
}

\section{Contents}

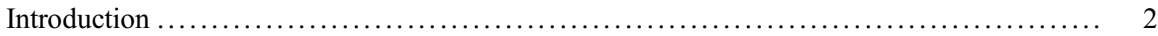

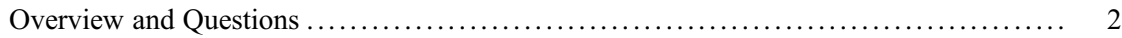

Literature Linkages Among Poverty, PD, Teacher Beliefs, and Instruction .............. 3

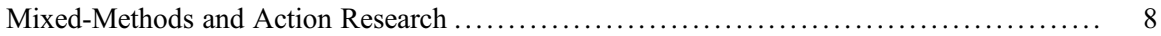

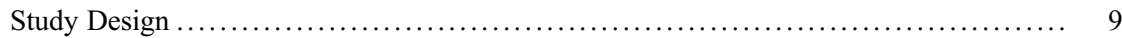

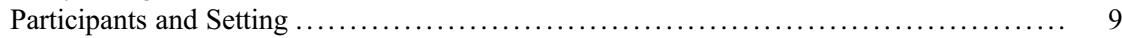

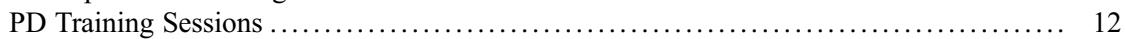

Findings Regarding Teacher PD, Beliefs, and Poverty ........................... 14

Teachers' Negative Biases Against People in Poverty Changed ....................... 14

Teacher Views of People in Poverty Became More Positive ........................ 15

Teachers Implemented Specific Strategies to Teach Students from Poverty ............. 16

Teachers Lacked Appropriate PD Training for Working with Students from Poverty ..... 17

Content, Components, and Structure of Teacher PD Training Matter ................. 18

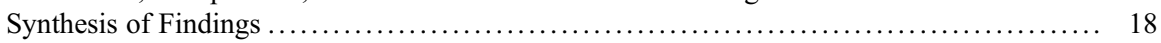

Implications and Recommendations for Practice and Policy ......................... 19

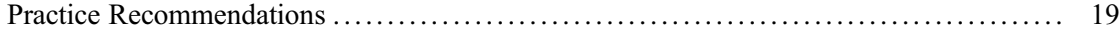

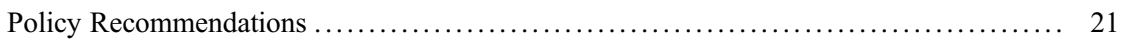

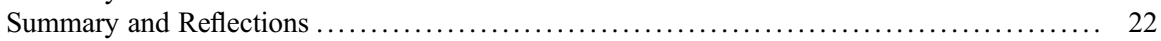

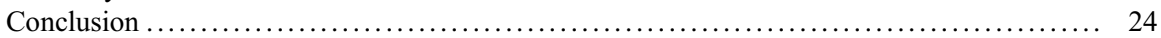

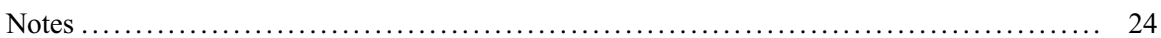

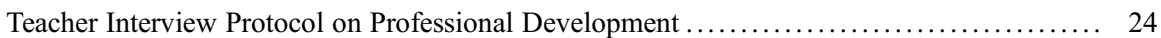

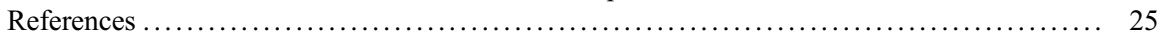

B. M. Wickham

Montgomery County Public Schools, Christiansburg, VA, USA

e-mail: bmwbarbi@vt.edu

C. A. Mullen $(\bowtie)$

College of Liberal Arts and Human Sciences, School of Education, VTCRC, Virginia Tech, Blacksburg, VA, USA

e-mail: camullen@vt.edu

C. A. Mullen (ed.), Handbook of Social Justice Interventions in Education,

Springer International Handbooks of Education,

https://doi.org/10.1007/978-3-030-29553-0_94-1 


\section{Abstract}

After nearly two decades of efforts to adhere to legal expectations for $\mathrm{K}-12$ public education in the United States, poverty still impacts student achievement. The purpose of this study was to discern the effects of practitioner-designed professional development (PD) on teacher beliefs/attitudes about students living in poverty. A mixed-methods approach, supported by an action research design, was used. Participants were 47 elementary teachers from 11 elementary public schools in southwest Virginia, USA. They completed a survey before and after the PD regarding their beliefs, knowledge, and experiences about working with students in poverty. Ten teachers at five Title I elementary schools were interviewed one-on-one following the PD workshop. The research focused on the creation and implementation of the PD and whether teacher beliefs changed after the intervention. Findings indicated that the PD and learning did, in actuality, impact teachers' beliefs, leading to changes in their instructional practices. This study could provide guidance to administrators, leaders, mentor teachers, academics, and others interested in facilitating effective PD for teaching students from low socioeconomic status (SES) backgrounds.

\section{Keywords}

Beliefs $\cdot$ Poverty $\cdot$ Instructional strategies $\cdot$ Interview $\cdot$ Professional development $\cdot$ Survey

\section{Introduction}

\section{Overview and Questions}

Poverty is one of the most significant factors influencing student achievement (Boyles and Mullen 2020; Jensen 2009; Wickham 2020). The No Child Left Behind Act (NCLB) of 2001 required educators to close the "achievement gap" for students in poverty. Annual testing in reading and mathematics was mandated, with data reported at the subgroup level for students of color and those with special needs, limited English proficiency, and low SES (Ladd 2017). The Every Student Succeeds Act, passed in 2015 to replace NCLB, maintained the provisions for annual testing and subgroup data reporting (McGuinn 2016).

Federal accountability legislation resulted in educators spending a great deal of time identifying how groups of students differ in the attempt to reduce discrepancies in standardized test performance. Yet, after almost 20 years of implementing NCLB measures to close the "achievement gap" among "groups defined by SES, race/ ethnicity, and gender," the disparity in educational outcomes persists on "standardized test scores, grade point average, dropout rates, and college enrollment, completion rate, etc.” (Lumen Learning n.d.; also, Ladd 2017). America's standardization of student learning and achievement "ignited a reevaluation of existing models of teacher professional development (PD)," which shifted the paradigm of 
the "stand-alone workshop to teacher learning that is embedded in daily practice" (Mullen and Hutinger 2008, p. 277).

Driving this US-based study was the research question, "To what extent does practitioner-designed PD impact teacher beliefs regarding students from poverty?" Secondary questions addressed targeted PD within a temporal timeframe: (1) What do teachers believe about students who live in poverty prior to participating in targeted PD? (2) How do teacher beliefs change after participating in targeted PD? (3) How do teachers adjust their use of instructional strategies after participating in targeted PD?

\section{Literature Linkages Among Poverty, PD, Teacher Beliefs, and Instruction}

Regarding the language we use and our definitions of key concepts, achievement gap is restricted to the policy and academic discourses from which it arises. Otherwise, we demonstrate a social justice mindset by using opportunity gap (which signals a deep gap in wealth and tremendous inequities in access to education) to direct attention to how people's contexts affect their outcomes or opportunities. Contextual and cultural differences and systemic inequities influence individuals' circumstances as well as plague classrooms and schools. Poor learning conditions, exacerbated by inequitable distribution of funding, quality teachers, and so forth, not only deprive students of a meaningful education but also their right to an equal education. So that teachers will be able to "teach diverse learners equitably" and make available opportunities for all students to engage in "deep learning" - in light of twenty-first century capabilities like a novel and critical thinking needed within the knowledge era, they need to have opportunities to develop themselves (Darling-Hammond and Oakes 2019, p. 4).

Darling-Hammond (as cited in Warren 2018) has long argued for the preparation of a teaching workforce that is equipped to teach for social justice. This wholesale change necessitates a different worldview reflected in a shifting discourse (e.g., from achievement gap to opportunity gap) to convey a racially and socioeconomically sensitive perspective: "The opportunity to learn - the necessary resources, the curriculum opportunities, the quality teachers - that affluent students have is what determines what people can do in life" (p. 18). Advocacy for child wellness in highpoverty environments involves granting opportunities (ranging from providing resources for improving school performance to giving low-income families access to safe neighborhoods with better living conditions) to low-income children and youth that build capacity for learning and academic success (Mullen 2014). In contrast, achievement gap "does not account for the lack of opportunities and exposure many children of color and low-income students live with outside the classroom"; it also fails to "explain the [plight of] millions of children who go to school in poverty stricken neighborhoods" (Patrick 2015).

It stands to reason, then, that focusing on overcoming limitations of poverty may be more useful in influencing children's lives than identifying differences among 
student groups (Burney and Beilke 2008). Despite the continued disparity in achievement, high-poverty, high-performing schools do exist (Suber 2012). Going above and beyond to support students from poverty in academic achievement is extremely important with the widening economic and educational gaps between high- and low-income families in the United States (Budge and Parrett 2018; Ladd and Fiske 2011; Mullen and Kealy 2013).

Despite educators' efforts to implement NCLB requirements, the opportunity gap in American schools has not been reduced (Ladd and Fiske 2011; Mullen and Kealy 2013). Obstacles to improving the academic achievement of students in poverty include teacher beliefs/attitudes, instructional strategies, and effective PD. Teacher beliefs and perceptions about students in poverty impact what children of low SES backgrounds can achieve, limiting opportunities in school and life (Archambault et al. 2012; Bomer et al. 2008; Budge and Parrett 2018; Dell'Angelo 2016; Gorski 2008).

Essential instructional strategies, identified for teaching students in poverty, have merit for all students (Budge and Parrett 2018; Jensen 2009; Schlechty 2011). Classroom strategies include providing structure, treating students with respect, having a positive attitude, teaching with enthusiasm, showing interest in students' lives, and using stories/storytelling in lessons (Meador 2020). Also, seven ways to teach, relate to, and validate low-income students are to:

establish a caring and believing environment; get to know each student's name; determine what each student is interested in; survey students to learn about family and daily practices; identify students' learning styles; allow students to "tell" their story; and build lessons based on information learned about the students. (Johnson 2013, p. 14)

However, problems with teacher preparedness persist, as does a knowledgeimplementation gap (Guskey 2000, 2009), indicating the need for targeted PD.

Helping impoverished students succeed demands an accurate picture of poverty and how it impacts their ability to thrive socially, emotionally, and academically (Jensen 2009). In the United States, "child poverty has grown to the point where a majority of children in public schools now come from low-income families" (Darling-Hammond and Oakes 2019, p. 3). Some teachers from a middle-class background may not be aware of just how widespread and severe poverty is for children. Or, they may struggle to understand why students from poverty think and behave the way they do (Payne 2005). It is essential to have knowledge about the culture of these children and youth, including family and community life, which can be burdened by "homelessness, food insecurity, lack of medical care, [and] frequent violence" (Darling-Hammond and Oakes 2019, p. 3). To this end, teachers could benefit from information and training about poverty-stricken living conditions (Jensen 2009; Johnson 2013). In fact, this course of action is strongly advised for teacher education programs, so that preservice teachers can be prepared for the realities of poverty and the multiple ways in which they will be called on to support learning for low-income students and their cultivation of "positive mind-sets and beliefs about self and school" (Darling-Hammond and Oakes 2019, p. 5). 
Teachers must also teach lower-class students hidden rules of the middle class to facilitate their success, insisted Payne (2005). Among middle-class rules, acceptance and love are conditional and largely based on achievement; values/driving forces are achievement, work, and self-sufficiency; the future is "most important," necessitating good choices in the present; and using a formal register of standard language is expected at school and work (Payne 2005). However, educators must also be exposed to hidden rules of the lower class (and the wealthy class) to develop a perspective on cultural and SES differences.

Leaders, scholars, and other stakeholders have been urged to research and facilitate effective PD to impact teacher beliefs about students from poverty, implement instructional strategies with the best chance of success, and ensure that policies are in place to support this transformative work. To Rubie-Davies et al. (2012), much more research is needed on "teacher beliefs" and "teacher factors, [which] are important to consider since beliefs mold thoughts and resultant instructional behaviors that, in turn, can contribute to student outcomes" (p. 270). The present study is a direct response to their recommendation.

Leadership is vital to this work. When strong leaders develop a culture in which continual learning is considered essential, PD is most effective (Moore et al. 2011). Because leaders can create policy and be the impetus for change (Schlechty 2002), they need to be involved in supporting professional learning experiences for educators. Through teachers who participate in effective PD that positively impacts student achievement (Cohen and Hill 2001) leadership teams can promote wholeschool reform.

The trite phrase "good instruction is good instruction" may be true for teaching all students. Bransford et al. (2007) argued that teachers who succeed with students in poverty use methods that reflect what research says about how people learn. They further contended that teacher knowledge of child development and cultural backgrounds is imperative for classroom modeling of student-centered pedagogies.

Poverty is a common factor impacting student achievement within and across all student subgroups for whom characteristics like socioeconomic status are similar (Reardon 2013). With the intensification of accountability measures over the past two decades, teachers have been searching for strategies to improve student performance. Educators must understand the hidden rules of the lower-income class and teach students from poverty the rules that will aid their success at school and in future work, according to Payne (2005) whose perspective guides her staff development program (see Payne 2018).

Other researchers, however, concluded that Payne's (2005) hypothesizing perpetuates teachers' deficit thinking about students from poverty, creating or reinforcing stereotypes of (perceived) weaknesses (Bomer et al. 2008; Budge and Parrett 2018; Gorski 2008). More current research even surmises that Payne's work may have caused more harm than good, as evidenced by the numbers of educators who continue to typecast children from low-income backgrounds (Gorski 2018). While ideological differences exist about poverty among Payne, Gorski, and Budge and Parrett, similarities exist in how they identified and approached instructional strategies, as we reveal in Table 1. It compares the three authorial perspectives. 
Table 1 Perspectives on poverty and instructional strategies for increasing impoverished students' achievement

\begin{tabular}{|c|c|c|c|}
\hline $\begin{array}{l}\text { Researcher } \\
\text { and } \\
\text { publication }\end{array}$ & Payne (2005) & Gorski $(2008,2018)$ & Budge and Parrett (2018) \\
\hline $\begin{array}{l}\text { Perspective } \\
\text { on poverty }\end{array}$ & $\begin{array}{l}\text { Generational } \\
\text { poverty can create } \\
\text { its own culture } \\
\text { with hidden rules }\end{array}$ & $\begin{array}{l}\text { Cultures of poverty do not } \\
\text { exist; poverty results from } \\
\text { structural barriers (e.g., the } \\
\text { inequitable distribution of } \\
\text { opportunities and } \\
\text { resources, and access to } \\
\text { them) }\end{array}$ & $\begin{array}{l}\text { Poverty is caused by } \\
\text { limited opportunities and } \\
\text { resources }\end{array}$ \\
\hline $\begin{array}{l}\text { Instructional } \\
\text { strategies }\end{array}$ & $\begin{array}{l}\text { Build } \\
\text { relationships } \\
\text { Develop literacy } \\
\text { skills } \\
\text { Hold high } \\
\text { expectations for } \\
\text { learning } \\
\text { Use data to guide } \\
\text { instruction and } \\
\text { intervention } \\
\text { Teach students } \\
\text { hidden rules of } \\
\text { the middle class } \\
\text { Teach mental } \\
\text { models for } \\
\text { abstract } \\
\text { information }\end{array}$ & $\begin{array}{l}\text { Build relationships } \\
\text { Develop literacy skills } \\
\text { Hold high expectations for } \\
\text { learning } \\
\text { Use data to guide } \\
\text { instruction and intervention } \\
\text { Embrace structural } \\
\text { ideology, the belief that } \\
\text { educational outcome gaps } \\
\text { are the result of structural } \\
\text { barriers like the unfair } \\
\text { distribution of opportunity } \\
\text { and access } \\
\text { Make real-world } \\
\text { connections for students } \\
\text { experiencing poverty } \\
\text { because they lack vital } \\
\text { experiences }\end{array}$ & $\begin{array}{l}\text { Build relationships } \\
\text { Develop literacy skills } \\
\text { Hold high expectations for } \\
\text { learning } \\
\text { Use data to guide } \\
\text { instruction } \\
\text { Focus on disrupting } \\
\text { poverty by embracing } \\
\text { structural ideology } \\
\text { Teachers must reflect on } \\
\text { their own beliefs and } \\
\text { values to determine what } \\
\text { shapes their perception }\end{array}$ \\
\hline
\end{tabular}

Teaching students in poverty can manifest as lowered teacher expectations and distorted perceptions (Bomer et al. 2008; Budge and Parrett 2018; Gorski 2008; Jensen 2009). Bradley and Corwyn (2002) proposed that "teacher attitudes and expectations may be part of a complex set of mediators linking low SES to school failure and behavior problems"; in fact, "teachers provide poor children with less positive attention and less reinforcement for good performance" (p. 382). Archambault et al. (2012) argued that teachers' self-reported beliefs directly influence the quality of students' academic experiences, explaining that teachers who convey to students that they can succeed can positively impact their achievement.

Teacher beliefs about students can become a child's reality in the classroom and life. Dell'Angelo's (2016) multiple regression study showed that teachers' thoughts about barriers to learning are a strong predictor of student achievement. Gorski (2018) agreed, affirming specifically, that what teachers believe about people living in poverty informs how they teach and interact with individual students. Common judgment about why people are impoverished is saturated with a host of negative assumptions, such as they make bad choices in life, have moral failings (e.g., recklessness, laziness, and apathy toward school), are uneducated and lack a work 
history, do not have goals or are aimless, and so forth (Budge and Parrett 2018; Gorski 2018). Society's stigmatizing and shaming dynamics can be witnessed among educated citizens and in public schools.

Teachers who hold deficit views of students in poverty are expected to struggle with helping them academically. An explanation is that these teachers will work to "fix" the student rather than confront the structural barriers and inequitable systems that historically disadvantage economically marginalized families (Gorski 2018; also, Patrick 2015; Warren 2018). For example, low-income parents in rural areas who work multiple jobs or lack transportation will find it challenging to attend family events at school, thereby missing out on networking and learning what can be done to support their children (Boyles and Mullen 2020). Educators with a deficit lens or wealthy social class worldview may judge such scenarios as evidencing parental apathy and, specifically, indifference to one's own child's education, wellbeing, and future.

Educator-focused training is considered indispensable for "remedying" teacher beliefs about cultural and ethnic deficiencies if public school cultures are to become truly inclusive (Gorski 2018; Mullen and Kealy 2013). It needs to become widely understood that opportunity gaps for impoverished students exist due to inequities in the distribution of access and opportunity, not deficiencies in mindsets, cultures, or individuals (Gorski 2018; Patrick 2015; Warren 2018).

Critical issues of opportunity related to access, equity, power, privilege, and impact should not be overlooked. Theories of child wellness and development are essential for deepening teachers' understanding and propelling their advocacy inside and outside the classroom:

Child wellness needs to be understood holistically so that children and youth from highpoverty environments can succeed in schooling and life. The developing role of teacher as advocate of students' well-being is of pressing importance as a national and international agenda. Teachers who foster advocacy thinking and identities for themselves are well equipped to teach students to take ownership of their own well-being. Such actions can enrich the classroom curriculum and mitigate the negative effects of student learning in disadvantaged environments and segregated educational systems. Children and youth can benefit from teachers' capacity to facilitate the lifelong capacity of learning to advocate for one's self and others. (Mullen 2014, p. 157)

Studies on instructional strategies that increase the achievement of students in poverty have revealed discord among researchers as to whether specific strategies can impact their success or whether good teaching that works for all students will also work for children and youth from distressed circumstances. It is thought that best classroom practice for students, in general, may also apply to economically marginalized populations (Antonetti and Garver 2015; Bransford et al. 2007; Budge and Parrett 2018).

Regardless, researchers repeatedly identify relationship-building as an essential strategy for understanding students' backgrounds and creating learning environments conducive to success (Budge and Parrett 2018; Jensen 2009; Payne 2008; Schlechty 2002). Holding high expectations for students is also frequently cited as a 
strategy for helping students in poverty become more successful (Budge and Parrett 2018; Gorski 2008; Jensen 2009).

Well-designed, appropriate training can ensure that teachers have the tools needed to support students in poverty (Gorski 2018). However, Garet et al.'s (2001) regression analysis indicated that little research is available to demonstrate the impact of teacher PD on student achievement. Gorski (2018), drawing upon multiple research sources, suggested that with appropriate and effective training, teachers can closely examine their own beliefs and biases to better understand the low SES students they teach.

Many researchers have tried to determine the impact of PD, with less success than may be expected (e.g., Guskey 2000). Additional research is warranted to thoroughly investigate teachers' impact on the academic achievement of students in poverty following PD that targets beliefs and specific high-yield instructional strategies. Evaluation typically follows the implementation of specific commercial programs, but not those designed by practitioners and district leaders. As the current opportunity gap indicates, the PD most teachers experience today is not providing the knowledge and skills that yield transformative classrooms and sustained systemic change.

While the impact of PD on student achievement is inconclusive, researchers continue to work to identify characteristics of high-quality PD that increase teachers' potential for influencing student achievement. Within the context of NCLB, it has been said, "Never before in the history of education has greater importance been attached to the [PD] of educators" (Guskey 2000, p. 3). Grant et al. (2008), who suggested that continuing teacher PD supports student achievement, asserted that the single most influential school factor affecting student achievement is the teacher. For teachers to see an increase in student achievement, they must be constantly learning, yet many PD interventions fall short of addressing how student results can be improved. In contrast, PD designed by practitioners around relevant topics, implemented in the workplace and with support for teachers, yields the most benefit for both educators and students (Croft et al. 2010; Grant et al. 2008; Guskey 2000).

\section{Mixed-Methods and Action Research}

Wickham (2020), the lead author and a director of elementary education, investigated teacher beliefs about impoverished students in relation to a PD intervention. (This chapter, which is from that larger, unpublished work, selectively represents and updates it.) The research purpose was to ascertain the impacts of newly implemented PD on teachers' values and assumptions, as well as instruction of low-income students. Besides contributing to the literature, another goal was to generate evidence-based findings to help education leaders make informed decisions about the professional learning experiences they can implement to assist teachers. 


\section{Study Design}

An action research design was combined with mixed methods. Action research design allows specific phenomena to be targeted for interpretive analysis and improvements made while spurring change in policy and practice (Mullen et al. 2015). Survey and interview information was collected, with quantitative analyses of the survey data and qualitative analyses of the interview data. Action research lends itself to qualitative designs and opportunities for educators to reflect on particular experiences, examine their beliefs and biases, and expand their repertoire (Mullen et al. 2015; Stringer 2008; Weisman and Garza 2002). The generation of quantitative and qualitative data allowed for in-depth analysis and data triangulation.

The exhaustive methodological design comprised four components: a pre- and post-survey instrument, PD training intervention, and interview. Pre- and postsurvey instrument design permitted flexibility for engaging in and measuring interventions. The validated survey instrument, which belongs to Budge and Parrett (2018), is viewable in Table 2. Their inventory has a section pertaining to beliefs and another to instructional strategies, both of which were administered in the larger study (i.e., Wickham 2020). However, we are reporting only on the beliefs portion here due to space restrictions.

Budge and Parrett's 2018 instrument was selected for the study (and PD teacher training) because of its focus on poverty and the disruption of it and because it was a self-inventory inviting reflection and change. The self-inventory was extended with questions eliciting teachers' demographic information and previous training addressing students from poverty. The prompts were organized around the teachers' beliefs regarding people from poverty, their knowledge of working with impoverished students, and their beliefs about their ability to impact instruction.

The pre- and post-surveys, PD training, and interview data were collected on four interrelated levels: (1) the origins of teacher beliefs about people from poverty, (2) teacher beliefs about students' ability to learn, (3) the impact of the PD on teacher beliefs about low-income students, and (4) the impact of trainings on instructional strategies implemented in the classroom.

The interviews, held after the PD training sessions and post-survey, served as a conduit for eliciting information about how to improve the PD training in the future. All interviewees completed PD feedback sheets to this effect.

\section{Participants and Setting}

Voluntary survey respondents $(N=47$; 45 females; all but one White; aged 20s-40s) were full-time teachers from 11 elementary schools who taught grades $\mathrm{K}-5$ and core content in reading, math, science, and/or social studies, with special education represented. Most $(61.7 \%)$ had 3 or more years of teaching experience. While new to the schools in which they were teaching, this was not an issue for the purposes of the study or PD training. The interviews, which brought focus to teacher beliefs about poverty and instructional strategies used in teaching, did not begin until 


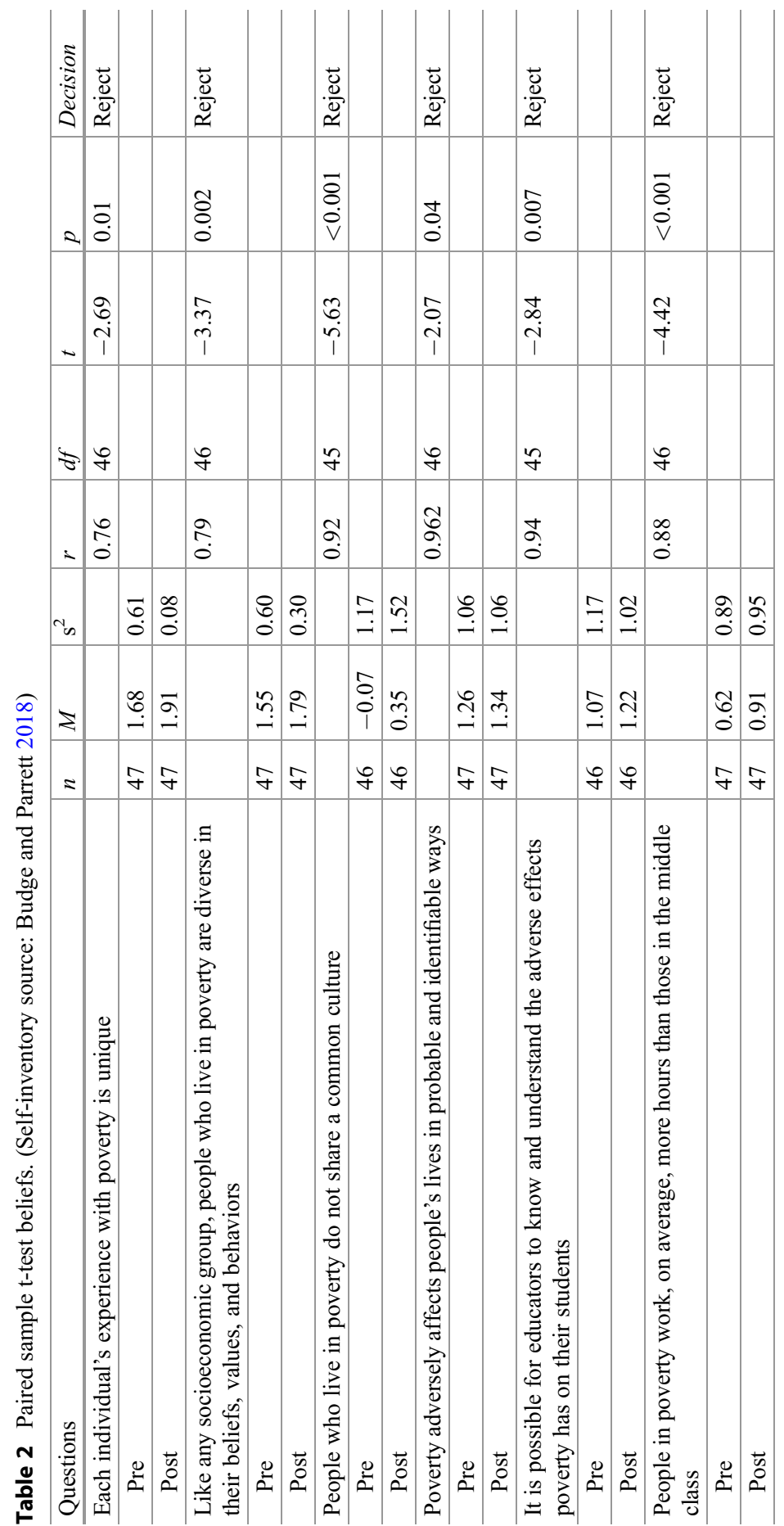




\begin{tabular}{|c|c|c|c|c|c|c|c|c|c|}
\hline 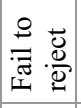 & & $\frac{\vec{s}}{\mathscr{a}}$ & & 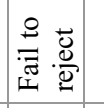 & & 离 & 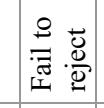 & & : \\
\hline & & $\begin{array}{l}\bar{\partial} \\
\dot{\vec{v}}\end{array}$ & & 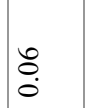 & & $\begin{array}{l}0 \\
0 \\
0 \\
0\end{array}$ & 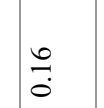 & & ठ্े \\
\hline & & $\vec{a}$ & & $\frac{1}{4}$ & & $\begin{array}{l}\hat{b} \\
\dot{i}\end{array}$ & $\stackrel{\text { fo }}{i}$ & & $\begin{array}{l}0 \\
\dot{p} \\
i\end{array}$ \\
\hline & & 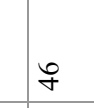 & & 8 & & t & o & & $f$ \\
\hline & & $\begin{array}{c}\infty \\
\infty \\
0 \\
0\end{array}$ & & $\hat{a}$ & & $\ddot{a}$ & aे & & $\stackrel{\infty}{\infty}$ \\
\hline & $\overbrace{0}^{\infty}$ & & $\stackrel{\substack{\infty \\
\hdashline}}{\infty}$ & & తి & f & & 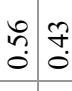 & ְุ: \\
\hline & ذָذ & & $\begin{array}{ll}0 \\
0 \\
0\end{array}$ & & తొ: & 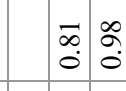 & & $\stackrel{q}{\rightarrow} \stackrel{n}{=}$ & $\tilde{\sigma}=$ \\
\hline & to & f & f & & f f & f & & f & f: \\
\hline 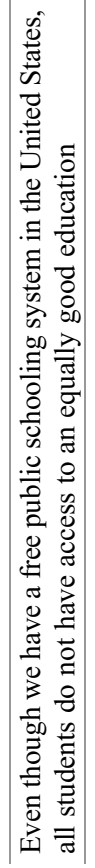 & & 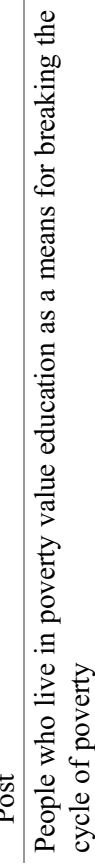 & & 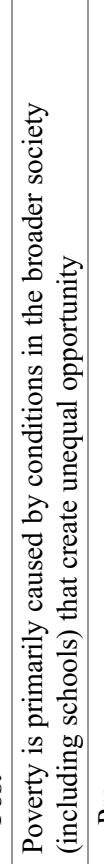 & & 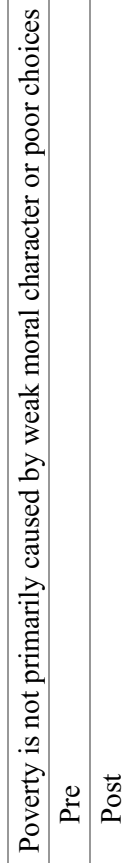 & 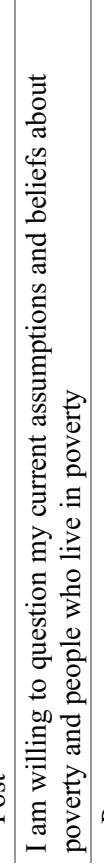 & . & 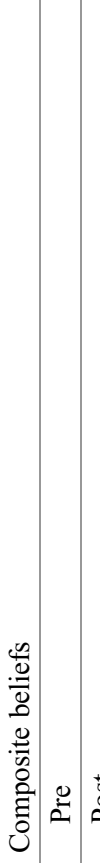 \\
\hline
\end{tabular}


mid-October 2019; with the school year starting mid-August, the 10 interviewees had 2 months to teach in their new classrooms and all had previously taught low SES students.

The 11 schools in which all 47 teachers worked were located in rural southwest VA; 7 of them were Title 1 schools with low SES, and 4 of them were high SES or non-Title 1 schools. To clarify, Title 1 is a federally funded educational program in the United States for a student population that is at least $40 \%$ eligible for free or reduced-price lunch. Students who populate high-poverty schools are mainly Latinx, African American, and American Indian/Alaska Native, with the smallest percentage being White (U.S Department of Education 2019).

Due to the potential for early intervention to reduce poverty's impact on children, teachers working with the youngest children satisfied eligibility as potential participants for the study, following the logic of Brooks-Gunn and Duncan (1997), who asserted that "children who experience poverty during their preschool and early school years" are less likely to complete school than students who experience poverty only in later years (p. 55).

After completing the survey, the teachers participated in the practitioner-designed training, exploring their beliefs about students from low SES families while learning about and practicing effective instructional strategies. Voluntary consent was obtained from 47 participants (6 additional teachers completed the PD intervention and chose not to participate in the study).

The interview sample $(n=10)$, drawing upon the survey pool, consisted of participants from 5 Title 1 schools. Following the PD training sessions, a subset of teachers was invited to be interviewed. Participating in this portion of the study was elementary teachers who engaged in the $\mathrm{PD}$, completed the two surveys, and taught in one of the division's seven Title I elementary schools. Of the 26 teachers who met these criteria, Barbara Wickham conducted 10 one-on-one interviews about the impact of the PD training on their beliefs and instructional practices.

\section{PD Training Sessions}

Fifty-three teachers (6 of whom were not study respondents) participated in $5 \mathrm{PD}$ training sessions over 10 weeks. These were designed to enable them to (1) examine their beliefs and perceptions about people from poverty, (2) review data and research about people living in poverty, and (3) practice effective instructional strategies for helping impoverished students succeed in the classroom. All workshop participants completed the survey before and after the PD regarding their beliefs, knowledge, and experiences working with students in poverty.

To create the PD workshops, Wickham collaboratively led a design team of administrators and instructional specialists. The design team completed a validation instrument to ensure that the content of the training addressed her research question and subquestions. The instrument was used to confirm that the training intentionally explored teacher beliefs, included effective instructional strategies from the literature review, and incorporated characteristics of teacher PD identified from sources. 
Open-ended questions were developed for the original instrument (see Appendix A: "Teacher Interview Protocol on Professional Development"). To ensure that the prompts were coherent, consistent with the research questions, and aligned with the literature reviewed, the design team conducted a review and provided feedback. By following these steps, content validity was satisfied (see Creswell 2012).

Using the literature review as a guide, the researcher developed the PD and learning experiences in consultation. Training dates were scheduled during teachers' contracted work time and designed specifically to meet adult learners' needs. Team members designed the content for each session, ensuring alignment with the research questions. A breakdown of the five workshops follows:

1. The first PD training session allowed time for the study to be explained and the survey to be taken.

2. The next session provided teachers with the opportunity to reflect on their beliefs about poverty and low-income individuals, and the origins of their ideas. The teachers explored data, facts, and case studies about people from poverty and confronted any negative stereotypes and biases. Building relationships with students and families was a focus.

3. This session addressed the elements of effective lesson plans and instructional strategies (e.g., holding high expectations for curriculum and student work and creating engaging tasks).

4. The fourth session continued the attention on building relationships, student engagement, and teacher beliefs about students from poverty.

5. The last session emphasized analyzing data, planning interventions, and providing specific feedback that motivates and encourages student growth.

Team members presented during the PD sessions, having agreed in advance that the workshops would be adjusted to meet the needs of participants based on their evolving feedback. This way of proceeding was in keeping with Herr and Anderson's (2005) assertion that, unlike traditional social science research that prohibits intervening in the research setting, "action research demands some form of intervention" to improve on what is already taking place (p. 5).

Quantitative and qualitative data analyses were performed. Descriptive statistical analysis was used for the demographic and survey data. Data from the initial survey were analyzed to ascertain teachers' beliefs about students from poverty and their knowledge and skills related to teaching such students. The initial survey also collected demographic information. After the completion of the PD, the survey was administered a second time. Data from the second survey were analyzed to determine the impact of the training. A paired sample t-test was used to determine if the training had an impact on teacher beliefs and knowledge.

Data were analyzed in relation to each research question. Interview responses were examined to identify emerging thematic patterns. Interview transcripts were reviewed for recurring keywords and phrases, important information, concepts from the literature review, and unexpected findings. 
The researchers triangulated the three data sources by reviewing the surveys, feedback from the PD sessions, and interviews. An educator experienced with qualitative inquiry and knowledgeable about educational literature independently examined a sample of the interview data. Minimal differences between the coding and analysis of the data were resolved and inter-rater reliability was established.

A final analysis of the data was conducted by synthesizing the quantitative analysis of the survey data with the qualitative analysis of the interview data to arrive at findings and conclusions. Comparing the initial and second survey results allowed for exploration of the impact of the training on teacher beliefs. Interview responses were analyzed to examine the impact of the training on teacher beliefs, implementation of instructional strategies, and teachers' perceptions of the impact of the training on student achievement. In addition, feedback from the training sessions was analyzed to examine whether teachers felt prepared to implement instructional strategies in their classrooms.

\section{Findings Regarding Teacher PD, Beliefs, and Poverty}

Six key findings emerged from the study, each of which is next elucidated. Following the descriptions is a synthesis of the data-based findings.

\section{Teachers' Negative Biases Against People in Poverty Changed}

Prior to participating in the targeted PD, teachers held multiple negative views about people who live in poverty. Pre-survey responses revealed that 29 of 47 teachers $(62 \%)$ believed that this population did not value education. Fifteen teachers (32\%) assumed that weak moral character or poor choices led to a life in poverty. Seventeen teachers (36\%) thought that people with low incomes worked fewer hours than those in the middle class, implying they did not work as hard.

These results map onto what researchers have been maintaining, such as Parrett and Budge (2009) who asserted that "Too many educators continue to believe that people who live in poverty share a common set of beliefs, values, attitudes, and behaviors such as a poor work ethic" and apathy toward school (p. 26). Gorski (2008) agreed, claiming that educators who believe that impoverished people do not value education will avoid addressing educational inequalities. Recognizing these issues, Mullen (2014) recommended that teachers harness the power of stakeholders (parents, leaders, and other community members) to not only discover resources that can make a difference to students in poverty but also to seek solutions to problems these student groups endure, including racial segregation and unsafe schools. When educators see students and student groups in terms of weaknesses, they tend to hold low expectations that can negatively impact achievement and even wellness. 


\section{Teacher Views of People in Poverty Became More Positive}

After teachers participated in the targeted PD, their perspectives changed, according to 8 (of the 11) questions about beliefs. Table 2 displays the results of the paired sample t-test for individual and composite scores related to beliefs (and excludes the results for instructional strategies from the larger Wickham [2020] study and omits the inventory's section on instructional strategies).

A statistically significant difference was apparent between participants' composite scores on questions pertaining to beliefs. Post-survey results revealed that more teachers believed that poverty is not primarily caused by weak moral character or poor choices (Mean Deviation $[\mathrm{MD}]=0.17 ; p=0.003$ ). Additionally, a greater number of teachers agreed that people who live in poverty do not share a common culture $(\mathrm{MD}=0.28 ; p<0.001)$. More teachers indicated that they believed people who live in poverty value education as a means for breaking the cycle of poverty $(\mathrm{MD}=0.64 ; p<0.001)$ and supported the belief that people in poverty work, on average, more hours than those in the middle class $(\mathrm{MD}=0.30 ; p<0.001)$. A preponderance of teachers believed it is possible to know and understand the adverse effects of poverty on their students $(\mathrm{MD}=0.15 ; p=0.007)$. More teachers also indicated the belief that poverty adversely affects people's lives in probable and identifiable ways $(\mathrm{MD}=0.09 ; p=0.04)$.

Following each PD session, the lead researcher (Wickham) met with the presenters to review and discuss participant feedback. The design team planned how to address topics for which participants requested additional support in future trainings. Feedback collected during PD sessions revealed that teachers were likely to implement strategies for communicating key messages regarding their positive belief in students. All teachers indicated that they would likely communicate to students the importance of the work, and $98 \%$ would likely convey "I won't give up on you."

Teachers' beliefs were positively impacted by the training sessions, according to interview responses. Eight (of 10) teachers interviewed believed that all students have the ability to learn, even though their learning may be impacted by a lack of access to resources. Seven individual mentions arose of teachers' concerns about stereotypes and biases regarding students from poverty. Eight teachers indicated that their beliefs were impacted by the training, and they described having a better understanding of the challenges faced by students in poverty. Four teachers described how the PD played a role in increasing their empathy for this economically vulnerable group.

Importantly, educators must examine their beliefs in light of conflicting theories about poverty because these impact what they do in their classrooms, what strategies (if any) they implement, and the effect on students and their success. Gorski (2008) suggested that operating from the structural-institutional perspective - understanding the confines of limited opportunities and resources on individuals - will grant teachers greater success with low SES student groups. 


\section{Teachers Implemented Specific Strategies to Teach Students from Poverty}

Teachers who completed the training reported having implemented the strategies to make a positive difference in their classrooms. In fact, post-survey results revealed a significantly statistical difference from pre-survey scores for seven out of the nine questions on instructional strategies and teacher knowledge, and a statistically significant difference between pre- and post-survey composite scores for instructional strategies.

After the PD, survey results uncovered that more teachers could explain why their expectations of students matter and how they influence the kind and quality of learning opportunities ( $\mathrm{MD}=0.15 ; p=0.02$ ). More teachers indicated that they were able to identify multiple ways poverty adversely affects lives and learning $(\mathrm{MD}=0.47 ; p<0.001)$ and practices that perpetuate inequity in the classroom $(\mathrm{MD}=0.51 ; p<0.001)$. A greater number of teachers indicated being able to identify multiple strategies for leveling the playing field for students from poverty $(\mathrm{MD}=0.45 ; p<0.001)$. Importantly, survey results showed that teachers were more likely to believe that they are professionally responsible for the learning of each student $(\mathrm{MD}=0.45 ; p=0.01)$ and willing to make changes in their teaching practice, even changes of a significant magnitude $(\mathrm{MD}=0.21 ; p=0.01)$.

Feedback collected during the PD training sessions, then, suggested that participants were likely to implement the instructional strategies that were addressed. The sessions featured 48 topics pertaining to instructional strategies, including building relationships with students, using various effective instructional strategies, engaging and maintaining students in active learning, providing clear feedback to students, and using data to guide instruction. Over $50 \%$ of the teacher participants indicated that they were likely to implement 47 of the topics without further training or support (the exception was communicating with parents in a way that demonstrates an awareness of the others' views, which may not have been sufficiently addressed during the workshop). All teachers specified that they were likely to implement strategies for building trust and respect and showing courtesy to students and that they would set high expectations for them by communicating the importance of the work. Most (96\%) responded that they were likely to communicate to students their belief in their ability and willingness to help them persevere.

Interview responses indicated that teachers had already been experimenting with the implementation of numerous instructional strategies from the training sessions. At the interviews, the 10 teachers from Title I schools frequently discussed strategies for building relationships, mentioning using techniques to gain knowledge about students 25 times. Six of these teachers reported having implemented engaging tasks learned during the PD. Teachers referred to creating engaging lessons that allow students to learn with others 13 times. Explaining why the lesson is important was described 16 times, and articulating the lesson objective as a means to make lessons more engaging was mentioned 12 times.

Operationalizing effective instructional strategies, such as holding high expectations and building relationships with students, can improve their academic 
performance (Budge and Parrett 2018; Gorski 2008; Jensen 2009). Marzano et al. (2001) confirmed that reinforcing effort and having high expectations are high-yield strategies for this purpose.

Building respectful relationships is a crucial intervention for improving achievement among low-income students (Payne 2008). High expectations for student work and curriculum is an instructional strategy that conveys what teachers believe about students and impacts what students become capable of achieving (Bomer et al. 2008; Budge and Parrett 2018; Gorski 2008; Jensen 2009). Gorski (2018) added that teachers who believe all their students are capable of reaching equal heights are open to each child's unique capabilities and individual struggles. Schlechty (2011) and Antonetti and Garver (2015) maintained that when teachers plan lessons with engaging qualities (e.g., real-world connections that encourage classmates to learn with peers and share personal responses), students can academically improve.

\section{Teachers Lacked Appropriate PD Training for Working with Students from Poverty}

Out of the 10 teachers interviewed, 5 revealed not having had prior training for appropriately teaching students from poverty; 28 of the 47 teachers surveyed after the PD indicated the same. All teachers interviewed shared concerns about the challenges that students from poverty face. They described how the obstacles caused by poverty impacted students' achievement and how low SES students begin school academically behind their wealthier peers. Interviewees specifically mentioned concerns around language and reading deficits. Teacher training targeting poverty and low SES groups should tackle specific areas of curriculum and teacher concerns in order to better prepare educators to address these barriers. With the pervasiveness of digital literacy, staying current with PD training interventions and follow-up assessments cannot be overstated.

Teacher training is necessary to ensure that teachers understand the students they teach, have an opportunity to thoroughly examine their own beliefs and biases, and are knowledgeable about effective instructional strategies to help low SES students succeed (Gorski 2018). Teachers can transform who they are by understanding that their "stereotypes about people in poverty are deeply embedded in our society and influence [their] mental maps" (Budge and Parrett 2018, p. 21). When students in poverty struggle in school, they may internalize a teacher's belief in their potential as a means to protect themselves and their pride or as motivation to offset other risk factors in their lives (Gregory and Huang 2013), suggesting that "positive expectations are additive and promotive for students regardless of their risk status" (Gregory and Huang 2013, p. 41). Students from poverty may adopt teachers' low expectations as a way to explain poor achievement, a cycle that reflective teachers can break. 


\section{Content, Components, and Structure of Teacher PD Training Matter}

Six (of the 10) teachers interviewed explained how the poverty simulation from the PD impacted their beliefs about impoverished students. Also, they thought that including additional simulations of living in poverty and teaching students from poverty would improve the PD's effectiveness. Eight of the teachers considered the PD impactful but overwhelming, indicating that having multiple opportunities to participate in the training over time would have helped to cement their new learning.

After each PD session, the teachers completed feedback forms, indicating which items they felt comfortable implementing on their own and which they wanted further training and additional support.

Bennett (2008) proposed that public school educators should study poverty and its impact on the school and community, thus changing their thinking and prompting them to action. Lindsey et al. (2010) also asserted that poverty should be rendered visible as a topic of discussion among school personnel. To facilitate this, PD is considered vital for enabling teachers' new learning, with the goal of enhancing student learning and improving achievement (Guskey 2000). Teacher training is most effective when strong leaders develop a culture in which continual learning is deemed essential (Moore et al. 2011). Because leaders can create policy and spur change (Schlechty 2002), they need to be involved in PD that targets experiential learning for educators. The present study reinforces the stance that ongoing, effective teacher PD positively impacts student achievement.

\section{Synthesis of Findings}

Analysis of the pre- and post-survey results indicated a statistically significant difference in the mean scores for questions pertaining to beliefs and instructional strategies. Thus, the difference in means supports the conclusion that the PD had an impact on teacher beliefs and instructional strategies. As teachers completed training sessions, they gave feedback on strategies they intended to implement in their classrooms, as well as strategies for which they wanted additional support and training. Most participants indicated that they were likely to implement content from the training in their classroom.

Multiple teachers who participated in the PD sessions described them as impactful and helpful. Participants' perspectives about people from poverty were informed by their personal and teaching experiences. The belief they expressed was that students have the ability to learn but that it may be hindered by factors like home life and lack of resources. After the training, interviewees reported increased empathy, an expression of care, for students from poverty. They indicated that, following the PD, they were implementing relationship-building activities, were communicating their belief in students, and were more intentional about selecting strategies to increase engagement.

An overarching perspective was that practitioner-designed PD can positively impact teacher beliefs about students and people from poverty. PD designed by 
practitioners can also impact teachers' instructional choices in the classroom. The data analysis also revealed that teachers do not receive training specifically for teaching students from poverty and that the structure, content, and design of teacher PD matters.

\section{Implications and Recommendations for Practice and Policy}

The study's findings have implications for school administrators and higher education leaders who sponsor PD that addresses teaching students in poverty. We first address recommendations for practice, then policy.

\section{Practice Recommendations}

Eleven recommendations for practice are:

1. Provide training for preservice teachers preparing them to work with low SES student populations. As previously indicated, the interviewees disclosed that they lacked explicit training in their college teacher preparation programs for working with impoverished students. Also, many shared that they had not interacted with students in poverty until their first year of teaching. Without specific training and repeated exposure, student teachers and beginning teachers will struggle to meet the needs of students in poverty, which may worsen teacher dissatisfaction and attrition.

2. Include diverse poverty simulations and real-world scenarios that convey an authentic sense of what it is like to be a student from poverty and a teacher working with impoverished groups. As reported, teacher interviewees indicated that the poverty simulation was the most impactful aspect of the training and that adding authentic scenarios would improve future trainings. When teachers understand how students perceive themselves and the impactful ways that others shape how children and youth understand their own potential and prospects in life, they can help students change negative self-thoughts. They can also influence the learning environment and school community.

3. Include opportunities for teachers to explore the origins of their beliefs and how those beliefs impact student achievement. As noted in the findings, teachers held more positive views of students from poverty after the PD training. Teachers must know who they are and be able to monitor and change their own biases in order to disrupt poverty (Budge and Parrett 2018). The results of the current study are hopeful, suggesting that beliefs can change and that it is possible for educators to know and understand the very real impact humans have on individuals from poverty.

4. Focus on explicit strategies for making classrooms engaging and learning environments interactive. As reported earlier, the survey results, PD session feedback, and interview responses indicated that teachers recognized the 
importance of strategies that make instruction engaging. Because students raised in poverty are subject to stressors that undermine school behavior and performance, it is especially important to provide teachers with strategies to engage them in learning (Jensen 2009).

5. Integrate explicit strategies for building relationships with students and families. As explained, the teachers found relationship-building strategies to be especially valuable when working with low-income students. Building relationships with economically marginalized groups is expected to yield an increase in achievement (Budge and Parrett 2018; Gorski 2008; Jensen 2009) and enhance well-being. Teachers recognized the value of relationship building and knowing their students. Interview and PD feedback responses from the present study, however, indicated that relationship-building strategies were not consistently integrated throughout the school day. Strategies for developing relationships should be ongoing rather than only implemented at the beginning of the school year or day.

6. Consider action-research designs for creating and implementing PD. Action research is practical, informs decision-making, and is directly relevant to classroom instruction and learning (Stringer 2008). As reported earlier, teachers repeatedly requested extra support with PD topics. Practitioners with expertise in each topic were able to adjust training sessions to meet teachers' needs. Action research enriches organizations through questioning, experimentation, peer work, and collaboration (Mullen et al. 2015).

7. Be mindful of the needs of adult learners. Diversity-minded collaboration among educators immersed in action research to address significant problems (e.g., lack of diversity in an organization) can make professional learning more effective while reculturing learning organizations to diversity and change (Mullen et al. 2015). Guskey (2009) warned that more time in training does not automatically equate to better PD. As stated earlier, several interviewees expressed feeling overwhelmed by the district's new teacher training, as in "I would love [to see the training over again] because I feel like some of it went in and then I didn't have any capacity to keep it there." More interviewees indicated that training delivered over a greater period of time (i.e., beyond the 10-week window) would have better supported their learning needs.

8. Involve administrative leaders in teacher PD, which is most effective when leaders develop a culture wherein continual learning is considered essential. As indicated, teachers requested ongoing support. School leaders must recognize the value of high-quality, high-impact PD and encourage teachers' participation. Principals' central involvement in PD initiatives increases the likelihood of teacher learning within their schools being embedded and sustained (Moore et al. 2011), and in ways that promote "high-quality instructional development" for the benefit of "student learning" (Mullen and Hutinger 2008, p. 277).

9. Include strategies for building relationships among students. Promoting classroom communities is vital to the development of caring relationships with students from poverty (Budge and Parrett 2018). Nurturing classroom climates foster a sense of belonging and connectedness, and expressions of 
care. As reported earlier, it was found that teacher participants considered instructional strategies for creating student-centered relationships to be especially important to classroom success. Such strategies would have been worth highlighting in the training and will be remembered for the future.

10. Include trauma-informed pedagogy, acknowledging the role of trauma in impoverished students' lives. As found, all teachers interviewed shared concerns about how poverty impacts student success, a reminder that "poverty is more than an income level; it is a socially constructed identity that leaves scars of psychological impoverishment" (Hudson 2015, p. 111). Trauma-informed training can help teachers effectively contend with the adversity impoverished students face. Six "indicators of wellness" from UNICEF can assist with such training and a more comprehensive focus on "child wellness"; one such applicable indicator is "young people's sense of well-being (e.g., personal view of health as fair or poor, not liking school, or not feeling satisfied with their own life)" and another is "behaviors and risk (e.g., experiences of fighting or being bullied)" (Mullen 2014, p. 158).

11. Ensure that training is job-embedded. As also found, interview responses indicated that teachers recognized the need for continuously supporting students from poverty. One teacher shared the value of ongoing support: "Keeping [poverty-focused PD] at the forefront [is important] because we know in education, something can be really big for a year, and you do all this training and work, [but] there's no follow-up." Job-embedded PD is considered the most effective PD structure, and it is connected to longer-term strategies aimed at changing teaching practice and school culture (Croft et al. 2010).

\section{Policy Recommendations}

Three recommendations for policy are:

1. School boards and policymakers should support ongoing poverty-related training for all teachers. PD is key to helping teachers learn and improve achievement (Guskey 2000). Teachers are sometimes resistant to change, largely due to underwhelming support from school leaders (e.g., insufficient resources, including time); consequently, they may lack vital knowledge, skills, and abilities and required for implementing best practices (Fullan 1993a). As was found, numerous interview participants described this study's PD training as helpful, even suggesting that it be extended to veteran teachers, new teachers, and - we hasten to add - student teachers. Developing and implementing policy that requires all teachers to explore their beliefs about students from poverty and learn effective instructional strategies for working with these groups could boost teachers' competence, self-confidence, and performance. People change their practice after they have developed mastery, and mastery takes time (Fullan 1993b). 
2. School boards and policymakers should examine inequitable education practices and create policies that abolish those practices. As was found in the present study, many teachers were concerned about impoverished students being stereotyped and impacted by views that negatively impact their success. Students who struggle academically are more likely to be recommended for retention and special education services. Some policies and practices manufacture low achievement for students in poverty (Gorski 2008). School boards must confront policies and practices that reinforce low expectations, such as retention, tracking, disciplining, and special education. "Poverty-disciplining belief" rationalizes racial bias in referrals (Fergus 2019, p. 31) and inappropriately assigning students in poverty to special education happens in schools.

3. Policymakers and school boards should implement policies to support universal pre-kindergarten programs. As indicated, teacher participants expressed concern about challenges that low SES student populations endure. One challenge that was repeated in interviews was the gap in reading and vocabulary skills. Impoverished students usually attend school with fewer readiness-to-learn skills, including a much smaller vocabulary than their peers; as a result, the opportunity gap widens over time (Budge and Parrett 2018). With the potential of early intervention to reduce poverty's impact on children, policies and programs can be developed to fund pre-kindergarten and other initiatives.

\section{Summary and Reflections}

Practitioner-designed PD can positively impact teacher beliefs about students from poverty, and teachers can be guided to identify their biases. Indications were that teachers' beliefs changed owing to the PD training intervention we illustrated. Interviewees recognized that stereotypes exist about people from poverty. Several teachers conveyed having a better understanding of students from low SES backgrounds and increased empathy for them. Considering that teachers beliefs about people living in poverty inform how they teach and interact with students (Gorski 2018), the training specifically addressed teachers' beliefs, examined different causes of poverty, and provided facts about poverty-stricken populations.

In contrast with exposure to PD that is one-shot training, teachers will often adjust their use of instructional strategies after participating in well-designed, effectively delivered PD. Survey responses indicated that, following the PD training sessions, teachers were more willing to make changes in their practice for which they could identify strategies for teaching students from poverty. Training session feedback indicated that most teachers were likely to implement new instructional strategies. Communicating with parents in a way that demonstrates the guardians' view did not elicit support from participants. However, the design team recognized that this topic needed to be better addressed in future workshops. Interviewees described having more attention in the classroom on facilitating engaging learning tasks, conveying objectives and reasons for lessons, and ensuring that content has authentic, real-life 
connections. Antonetti and Garver (2015) addressed the importance of planning engaging, rigorous work for students from poverty, and implementing within emotionally safe environments.

Also, flexibly structured practitioner-designed PD, like the kind we implemented for teachers from 11 elementary schools, can better meet practitioners' needs - time is built in for eliciting and analyzing feedback and adjusting training components. The PD training sessions we described were continually adapted to accommodate reviewing strategies in accordance with teachers' requests for additional support. Design team members implemented PD sessions matched to their expertise, extending scaffolded support to teachers who seemed eager for more.

As revealed by this study, complex factors related to teacher beliefs impact the achievement of low SES students. The origins of teacher beliefs and willingness to confront those beliefs, and how those beliefs impact their relationships with students and families, are multifaceted. People's experiences with poverty may radically differ - there is no "culture" of poverty (Fergus 2019; Gorski 2018). Yet, "school practitioners often assume kids from low-income backgrounds belong to a distinct and dysfunctional culture" in which impaired behaviors thwart academic success and that people from poverty share negative attributes (are less able, intelligent, competent, capable, etc.); thus, schools, as a microcosm of society, can be pathologizing places that "justify racial disparities" in achievement and systems of punishment and reward (Fergus 2019, p. 31). Educators do not naturally instill in others positive beliefs about low-SES people, who are often from households and communities of color, or bring about social justice for populations that are economically marginalized (Starck et al. 2020). Continuous PD is but one factor that can improve the quality of schooling and life for students in high-poverty schools.

Because of all such impediments, PD training interventions, aimed at resocializing teachers, can reduce prejudice and mitigate destructive core beliefs (e.g., low-income people are worthless, cannot be trusted, and are a failure). These can also reculture institutions in the process of experimenting with interventions at a larger scale that model core values (e.g., equity) and monitor expectations (Mullen et al. 2015; Starck et al. 2020).

Even with the pronounced opportunity gap between students who are wealthier and poorer, there is hope: "Being raised in poverty is not a sentence for a substandard life" (Jensen 2009, p. 26). Children from poverty-stricken families can learn and achieve at high levels. Economically disadvantaged students' performance in classrooms and likely their wellness are directly connected to teachers whose beliefs matter. We can change the way we act by changing the way we think; educators who have the opportunity to examine their beliefs can change those beliefs, as well as their instructional practices. Policymakers and leaders should ensure that teachers have the training they need to meet the challenges of students impacted by poverty. School cultures must promote unbiased teacher beliefs and role modeling around quality teaching and learning. 


\section{Conclusion}

A teacher's influence cannot be exaggerated and should not be underestimated in high-poverty schooling environments. Because teachers are the single most important dynamic affecting student achievement, they have a tremendous responsibility to foster student growth. Thoughtful practitioner-designed PD can influence teacher beliefs and equip classroom practitioners with effective instructional strategies, giving them the confidence and tools for helping impoverished children and youth succeed. Individuals with the authority and power to enact change are being asked to exert their agency on behalf of social justice for economically marginalized populations. District leaders can stimulate policy change, set high expectations for educators and teacher training, and establish guidelines for PD so that teachers receive preparation in the poverty plight. Teachers and leaders are being challenged in unprecedented ways - poverty in uncertain times, exacerbated by the COVID-19 pandemic in 2020, calls upon them in entirely new ways. As stakeholders in education, we must do everything possible to enable students to overcome poverty and realize their full potential.

\section{Notes}

Budge and Parrett's (2018) inventory, partially shown in Table 2, was utilized with permission upon payment from ASCD, the copyright holder, on May 12, 2020.

The study was approved in 2019 by Virginia Tech's federally approved Institutional Review Board and the non-identifying Virginia school division in which it was conducted. For interest in this chapter, contact Dr. Wickham $<$ bmwbarbi@vt.edu $>$.

\section{Teacher Interview Protocol on Professional Development}

1. Briefly highlight your teaching experiences this year.

2. Where do your ideas about poverty and people from poverty come from?

3. What do you believe about poor students' ability to learn? How did you come to your beliefs?

4. How were your beliefs about students from poverty impacted by the professional development you received this year?

5. Describe the relationship-building activities you implemented in your classroom this year.

6. What are some other ways you worked to build relationships with your students?

7. What are some strategies you implemented to make your instruction engaging for students?

8. How did you continually ensure clarity of objectives (that is, why the work is important for students) and criteria for success?

9. How do you communicate high expectations for student work? 
10. How did what you learned in the training affect your choice of instructional strategies after participating in the targeted professional development?

11. How do you think the training could be improved in the future to better meet the needs of teachers?

12. Is there anything else you would like to share?

\section{References}

Antonetti, J., \& Garver, J. (2015). 17,000 classroom visits can 't be wrong: Strategies that engage students, promote active learning, and boost achievement. Alexandria: ASCD.

Archambault, I., Janosz, M., \& Chouinard, R. (2012). Teacher beliefs as predictors of adolescents' cognitive engagement and achievement in mathematics. Journal of Educational Research, 105(5), 319-328.

Bennett, M. (2008). Understanding the students we teach: Poverty in the classroom. Clearing House, 81(6), 251-256.

Bomer, R., Dworin, J., May, L., \& Semingson, P. (2008). Miseducating teachers about the poor: A critical analysis of Ruby Payne's claims about poverty. Teachers College Record, 110(12), 2497-2531.

Boyles, E. T., \& Mullen, C. A. (2020). Principals' responsibility for helping impoverished students succeed in rural Appalachia. In C. A. Mullen (Ed.), Handbook of social justice interventions in education (pp. 1-26). Cham: Springer.

Bradley, R., \& Corwyn, R. (2002). Socioeconomic status and child development. Annual Review of Psychology, 53(1), 371-399.

Bransford, J., Derry, S., Berliner, D., Hammerness, K., \& LePage, P. (2007). Theories of learning and their roles in teaching. In L. Darling-Hammond \& J. Bransford (Eds.), Preparing teachers for a changing world: What teachers should learn and be able to do (pp. 1-87). San Francisco: Jossey-Bass.

Brooks-Gunn, J., \& Duncan, G. (1997). The effects of poverty on children. The Future of Children, $7(2), 55-71$.

Budge, K., \& Parrett, W. (2018). Disrupting poverty: Five powerful classroom practices. Alexandria: ASCD.

Burney, V., \& Beilke, J. (2008). The constraints of poverty on high achievement. Journal for the Education of the Gifted, 31(3), 295-321.

Cohen, D., \& Hill, H. (2001). Learning policy: When state education reform works. New Haven: Yale University Press.

Creswell, J. (2012). Educational research: Planning, conducting, and evaluating quantitative and qualitative research (4th ed.). Upper Saddle River: Pearson Education.

Croft, A., Coggshall, J., Dolan, M., \& Powers, E. (2010). Job-embedded professional development what it is, who is responsible, and how to get it done well. [Report]. Retrieved from https:// learningforward.org/wp-content/uploads/2017/08/job-embedded-professional-development.pdf

Darling-Hammond, L., \& Oakes, J. (2019). Preparing teachers for deeper learning. Cambridge, MA: Harvard Education Press.

Dell'Angelo, T. (2016). The power of perception: Mediating the impact of poverty on student achievement. Education and Urban Society, 48(3), 245-261.

Fergus, E. (2019). Confronting our beliefs about poverty and discipline. Phi Delta Kappan, 100(5), $31-34$.

Fullan, M. (1993a). Change forces: Probing the depths of educational reform. Bristol: Palmer Press.

Fullan, M. (1993b). Why teachers must become change agents. Educational Leadership, 50(6), $12-17$. 
Garet, M., Porter, A., Desimone, L., Birman, B., \& Yoon, K. (2001). What makes professional development effective? Results from a national sample of teachers. American Educational Research Journal, 38(4), 915-945.

Gorski, P. (2008). The myth of the culture of poverty. Educational Leadership, 65(7), 32-36.

Gorski, P. (2018). Reaching and teaching students in poverty: Strategies for erasing the opportunity gap (2nd ed.). New York: Teachers College Press.

Grant, L., Stronge, J., \& Popp, P. (2008). Effective teaching and at-risk/highly mobile students: What do award-winning teachers do? [Report]. Retrieved from http://www.schoolturnar oundsupport.org/sites/default/files/resources/eff_teach.pdf

Gregory, A., \& Huang, F. (2013). It takes a village: The effects of 10th grade college-going expectations of students, parents, and teachers four years later. American Journal of Community Psychology, 52(1-2), 41-55.

Guskey, T. (2000). Evaluating professional development. Thousand Oaks: Corwin.

Guskey, T. (2009). Closing the knowledge gap on effective professional development. Educational Horizons, 87(4), 224-233.

Herr, K., \& Anderson, G. (2005). The action research dissertation: A guide for students and faculty. Los Angeles: SAGE.

Hudson, N. (2015). The trauma of poverty as social identity. Journal of Loss and Trauma, 21(2), $111-123$.

Jensen, E. (2009). Teaching with poverty in mind: What being poor does to kids' brains and what schools can do about it? Alexandria: ASCD.

Johnson, C. (2013). Leading learning for children from poverty: Six effective practices can help teachers help students from poverty succeed. Association for Middle Level Education, 1(4), $14-17$.

Ladd, H. (2017). No child left behind: A deeply flawed federal policy. Journal of Policy Analysis and Management, 36(2), 461-469.

Ladd, H, \& Fiske, E. (2011, December 11). Class matters: Why won't we admit it? The New York Times. Retrieved from https://www.nytimes.com/2011/12/12/opinion/the-unaddressed-linkbetween-poverty-and-education.html

Lindsey, R., Karns, M., \& Myatt, K. (2010). Culturally proficient education: An asset-based response to conditions of poverty. Thousand Oaks: Corwin.

Lumen Learning. (n.d.). Lumen learning education, society, \& the K-12 learner. [Courseware]. Retrieved from https://courses.lumenlearning.com/teachereducationx $92 \times 1$

Marzano, R., Pickering, D., \& Polluck, J. (2001). Classroom instruction that works: Researchbased strategies for increasing student achievement. Alexandria: ASCD.

McGuinn, P. (2016). From no child left behind to the every student succeeds act: Federalism and the education legacy of the Obama administration. Publius: The Journal of Federalism, 46(3), 392-415.

Meador, D. (2020, February 11). Strategies for teachers to develop positive relationships with students. ThoughtCo. Retrieved from thoughtco.com/develop-positive-relationships-with-stu dents-3194339

Moore, S. D., Kochan, F. K., Kraska, M., \& Reames, E. H. (2011). Professional development and student achievement in high poverty schools: Making the connection. International Studies in Educational Administration, 39(2), 65-78.

Mullen, C. A. (2014). Advocacy for child wellness in high-poverty environments. Kappa Delta Pi Record, 50(4), 157-163.

Mullen, C. A., \& Hutinger, J. L. (2008). The principal's role in fostering collaborative learning communities through faculty study group development. Theory Into Practice, 47(4), 276-285.

Mullen, C. A., \& Kealy, W. A. (2013). Poverty in school communities. Kappa Delta Pi Record, 49(2), 70-77.

Mullen, C. A., Rodríguez, M. A., \& Allen, T. G. (2015). Leaders learning from leaders as an emergent action learning strategy. Action Learning: Research and Practice, 12(3), 344-355. 
Parrett, W., \& Budge, K. (2009). Tough questions for tough times. Educational Leadership, 67(2), $22-27$.

Patrick, K. (2015). Why we need to stop calling it the 'achievement gap.' Education Post. Retrieved from https://educationpost.org/why-we-need-to-stop-calling-it-the-achievement-gap

Payne, R. (2005). A framework for understanding poverty (4th ed.). Highlands: aha! Process.

Payne, R. (2008). Nine powerful practices. Educational Leadership, 65(7), 48-52.

Payne, R. (2018). A framework for understanding poverty: A cognitive approach (6th ed.). Highlands: aha! Process. (Original, 1995, A framework for understanding poverty).

Reardon, S. (2013). The widening income achievement gap. Educational Leadership, 70(8), 10-16.

Rubie-Davies, C., Flint, A., \& McDonald, L. (2012). Teacher beliefs, teacher characteristics, and school contextual factors: What are the relationships? British Journal of Educational Psychology, 82(2), 270-288.

Schlechty, P. (2002). Working on the work. San Francisco: Jossey-Bass.

Schlechty, P. (2011). Engaging students: The next level of working on the work. San Francisco: Jossey-Bass.

Starck, J. G., Riddle, T., Sinclair, S., \& Warikoo, N. (2020). Teachers are people too: Examining the racial bias of teachers compared to other American adults. Educational Researcher, 1-12. https://doi.org/10.3102/0013189X20912758.

Stringer, E. (2008). Action research in education (2nd ed.). Upper Saddle River: Pearson Education.

Suber, C. (2012). Characteristics of effective principals in high-poverty South Carolina elementary schools. International Journal of Educational Leadership Preparation, 7(1). Retrieved from https://files.eric.ed.gov/fulltext/EJ971503.pdf

U.S. Department of Education. (2019). Concentration of public school students eligible for free or reduced-price lunch. [National Center for Education Statistics report]. Retrieved from https:// nces.ed.gov/programs/coe/indicator_clb.asp

Warren, J. (2018). School consultation for student success: A cognitive-behavioral approach. New York: Springer.

Weisman, E., \& Garza, S. (2002). Preservice teacher attitudes toward diversity: Can one class make a difference? Equity \& Excellence in Education, 35(1), 28-34.

Wickham, B. M. (2020). Designing effective professional development for teaching students in poverty: Impact on teacher beliefs and classroom practice (Unpublished doctoral dissertation). Virginia Tech, Blacksburg. Retrieved from https://vtechworks.lib.vt.edu/handle/10919/97519 